\title{
In-service Training in Preparing NESTs and NNESTs
}

\author{
Stephen J. Hall
}

\begin{abstract}
In-service training whether for native English speakers or non-native English speakers has seen a shift beyond a technical approach to greater ownership of the process by teachers. Issues abound in acceptance of so-called non-native speakers as teachers, yet commonalities exist in the profession when building expertise. Research has shown limited success with large-scale transmission techniques as a focus of professional development. This has led to adoption of reflective practice and group approaches. Pedagogy may also be used as a vehicle for teachers' own language development and it is in this area that differences which exist between nonnative English-speaking teachers (NNESTs) and native English-speaking teachers (NESTs) will be described. However, the core of success could well be in the teacher and teacher educator's relationship to drive acceptance of what could be novel techniques. Indicators of acceptance of change suggest that a collegial supportive approach through reflection and mentoring may be more beneficial than earlier approaches.
\end{abstract}

\section{Framing the Issue}

In the broadest sense, in-service (teacher) training (also known as INSET or continuing professional development) refers to a provision of organized programs for teachers who are currently serving in the field, usually with an intention to systematically support their ongoing development as language-teaching practitioners. Now constituting an integral part of second language teacher education literature, in-service teacher training has expanded both in terms of depth and width over the past couple of decades. In other words, depending on the context, it offers a range of professional development possibilities, opportunities, and practices (e.g., short-term in-school programs, team teaching, online discussion forums, international exchanges and visits, action/practitioner research endeavors, project-based learning tasks, supervision and mentoring, teacher inquiry communities and discussion groups, among others). Usually "in-service training" describes professional development activities for "working teachers" which may range from infrequent ad hoc workshops for large numbers to small group courses as part of long-term career development. Teacher education may involve individualized mentoring, reflective practice, or collaborative groups in well-resourced settings. In-service training, whether for native English-speaking teachers (NESTs) or nonnative English-speaking teachers (NNESTs), shares challenges in a wide range of institutional settings in English as a second language (ESL) and English as a foreign language (EFL) contexts. The profession could also recognize that both NESTs and NNESTs often bring the rich complexity of the personal experience of negotiating their identities as language users and teachers to the teacher education. Various approaches underpinning in-service training or teacher education are undertaken while teachers are already working in classrooms. In specific contexts where limited resources are available to education, this professional development may mean courses developing pedagogy and teachers' proficiency in classroom language to lead to formal qualifications.

Teachers in most settings want to see transferable and tangible returns during the education process undertaken in the middle of everyday classroom demands. As in-service training programs may occur in the midst of teaching careers, effective teacher educators need to ensure their effectiveness, overcome reluctance to change, and build acceptance through a shared The TESOL Encyclopedia of English Language Teaching. Edited by John I. Liontas. (C) 2017 John Wiley \& Sons, Inc. Published 2017 by John Wiley \& Sons, Inc. IN PRESS. 
sense of ownership and co-construction of the training process. This shared ownership could include the ownership of one's individual qualities as a language user and teacher, formulated in a contextualized manner sensitive to the past personal/professional background and future trajectories that one envisions as a language teacher. Bilingual or multilingual teachers may also have unique experiences underpinning their beliefs about language acquisition and this may be a strength which could be applied in classrooms. Teachers' beliefs about how learners acquire language and how classrooms are managed may impact on their acceptance of novel techniques or methods. This influence of teacher beliefs and sense of efficacy is in need of greater research, particularly for in-service contexts (Borg, 2011). Acceptance of change may be built on the usefulness of transferable tasks or respect for the trainer or teacher educator whose authority may come from experience, empowerment, and negotiation of personal and professional identity.

The acceptance of the ideologically infused, value-laden, highly contested, and dichotomously juxtaposed constructs of "native speaker" (NS) and "non-native speaker" (NNS) is however often based on bio-developmental features, and thus are a limiting perception undermining the complexity of what constitutes an effective English-language teacher or teacher educator. It has been argued that the very term "native speaker" and the favoring of the construct for teacher and teacher educator are problematic, both in definition and in practice-a phenomenon also known as "native speakerism" (Holliday, 2006). If there is a sense of dependency on the teacher educator from an attribution of authority based on this construct, application of techniques may be limited as the learning process may not be democratically and effectively co-constructed. Thus, in-service teacher education, in its least effective modes, may be reduced to rote training of a set of routines and techniques which structures classroom management solely from the teacher educators' perspective.

In-service teacher education may need to address both pedagogy and proficiency in terms of declarative and procedural knowledge (Pasternak \& Bailey, 2004) for teachers from a wide variety of backgrounds. Modelling pedagogy by contextualizing in-service education in the specifics of the local sociolinguistic and cultural background has been seen to be effective in creating a "buy in" to the adoption of new techniques. Some research suggests that teachers react positively to teacher education approaches which integrate pedagogy with communicative uses of English (Hall, 2013). Yet content knowledge about the language may not be sufficient when facing the complex demands of classroom interaction.

\section{Making the Case}

Whether referred to as "lifelong teacher development," "continuing professional development," or "in-service teacher training" (or INSET), the issue of teachers' ongoing development is comprised of a successful combination of two main axes: course versus schoolbased teacher learning, and school versus system-based priorities, as visually described in Figure 1. Thus, 'the 'teacher learning' and 'system' dimensions in the diagram should intersect and co-ordinate meaningfully with each other as well, to create the potential for an organic, holistic approach to meeting in-service teacher learning needs" (Waters \& Vilches, 2010, p. 4). This creates a more contextualized approach driven from the dimensions of content (situated within the "system"), aiming for an area of the methodology (derived from "teacher learning"). However, the ELT literature reports that there is a great tendency for in-service teacher training programs to be inadequately built, ad hoc, unidirectional and course or school-based programs, implemented in a top-down fashion and insensitive to the local realities and dynamics (affordances and constraints) that teachers are experiencing in their everyday practice.

The TESOL Encyclopedia of English Language Teaching. Edited by John I. Liontas. (C 2017 John Wiley \& Sons, Inc. Published 2017 by John Wiley \& Sons, Inc. IN PRESS. 
While there is relatively little in in-service training research, what there is pinpoints the importance of involving teachers in planning programs which are meeting everyday classroom needs while contributing to ongoing career growth. Active learning and reflective practice within teacher communities of practice have been found to be more effective than the top-down delivery of techniques (Farrell, 2013). Teachers learning together in communities of practice or teacher inquiry groups which examine shared problems are a developing area of research, drawing on practical in-service concerns. The site and scale of courses are important parameters as they not only impact on the effectiveness of pedagogic change but also impact on the return of investment into in-service teacher education. Increasingly there are moves away from large-scale courses to in-site or school-cluster group delivery. However, when teachers wish to adopt what has been learnt, the complexity of the context and administrative support structures can nurture or limit classroom change.

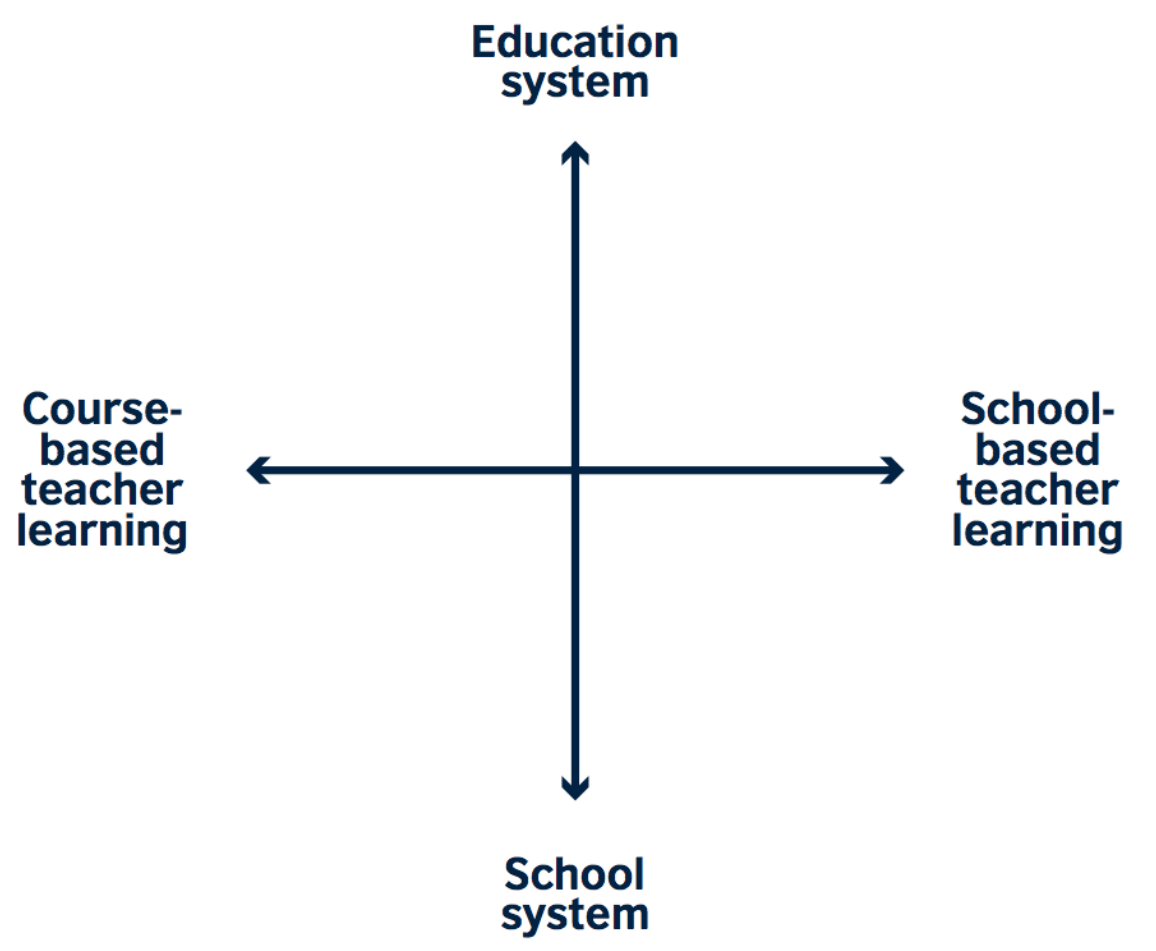

Figure 1 A “best practice” framework for INSET (Waters \& Vilches, 2010]

Recent developments in both in-service teacher training (highlighting the critical importance of ongoing teacher learning as a lifelong enterprise) and critical approaches to ELT (underscoring the issues of (in)equity, privilege marginalization, discrimination concerning NESTs and NNESTs) necessitate a closer link between these two lines of inquiry. Therefore, the necessity of addressing in-service training needs of NESTs and NNESTs is more relevant than ever. Clearly any teacher, regardless of their "label," will need to be proficient and confident as a language user and teacher; informed about the diverse uses, users, and functions of English as an international language; equipped with knowledge, skills, and dispositions in preparing language users for intercultural communication; an advocate of contextualizing educational practices in and beyond the classroom for 'glocal' interaction relevant to learners' lives, feelings, and aspirations; and well-versed in the roles that they play in the classroom. To better illustrate this need, Pasternak and Bailey (2004) argued that teachers, regardless of their "nativeness" status, must have both declarative knowledge (knowledge about language) and 
procedural knowledge (knowledge and ability to use language). More specifically, they argue that all teachers must be equipped with at least three key areas of knowledge: "(1) knowing about and how to use the target language, (2) knowing about and how to teach in culturally appropriate ways, and (3) knowing about and how to behave appropriately in the target culture" (p. 158). As demonstrated in Figure 2 by Pasternak and Bailey (2006) the fundamental axes informing teachers' practices (i.e., proficiency and professional preparation) are to be constructed in a multifaceted fashion, placed on a continuum, and are not to be viewed as an either-or proposition.

\section{Proficient in the target language}

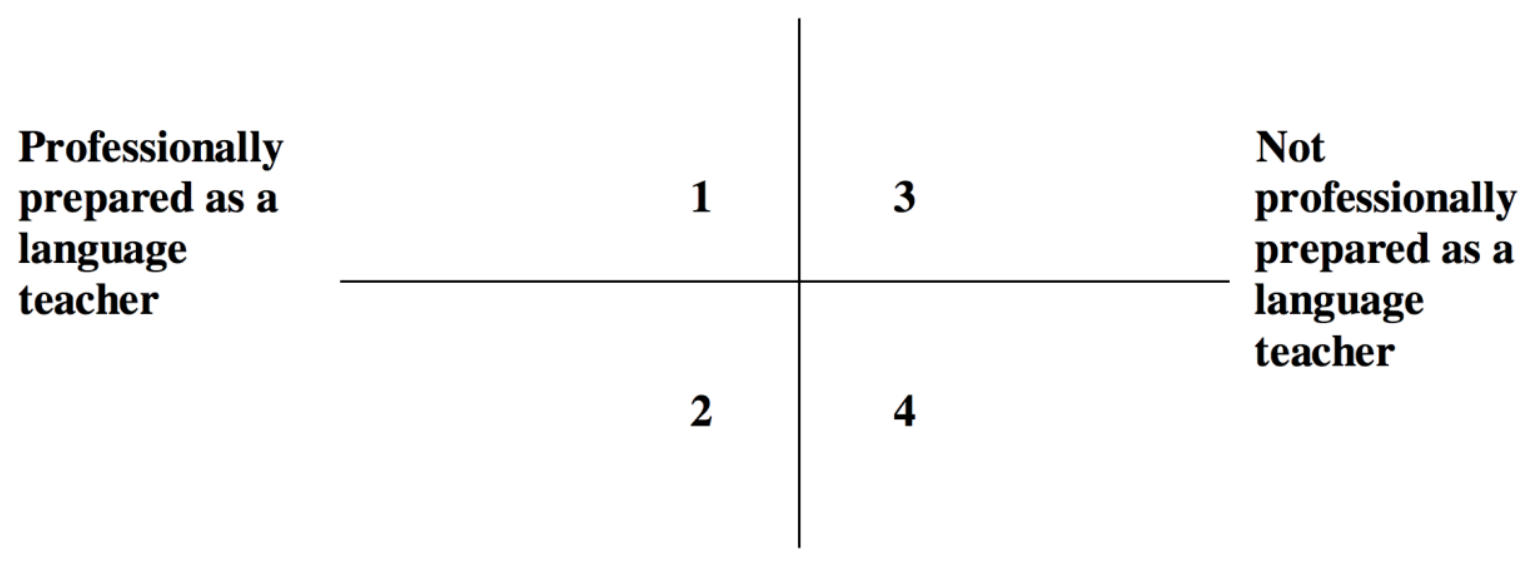

\section{Not proficient in the target language}

Figure 2 A continuum of target language proficiency and professional preparation (Pasternak \& Bailey, 2004)]

Building upon this conceptualization, it could be argued that teacher education programs, whether focused on pre- or in-service settings, need to provide a wide variety of opportunities, spaces, means, structures, and experiences promoting professional reflection; raising awareness of needs and advantages (constructed in a contextualized fashion, sensitive to individuals' past sociohistorical developments); and capitalizing on the importance of ongoing teacher development as a lifelong enterprise.

Research suggests that the dynamic of in-service teacher education change and transfer of skills depends on the interaction which teachers and trainers or teacher educators develop in a collegial rather than a hierarchical exchange. Industry has much to answer for a questionable hierarchy of promoting dichotomously formulated contested constructs (e.g., "NS versus NNS," "local versus foreign," "us versus them," "insider versus outsider") over the often rich linguistic, professional, and cultural repertoire of teachers from various backgrounds. Central to ownership of change may be situating teacher knowledge within specific classroom needs (Bailey, 2006, p. 59). There are a number of descriptions of collegial approaches which aim to deepen personal ownership of the teacher education process so as to co-construct teacher professional development beyond training in techniques, with most research being within preservice settings (Mann \& Hau, 2012). While the emphasis on teacher development research is 
often on the more accessible sites of pre-service training, in-service research is gaining increasing support as English develops as a lingua franca and investment in upskilling the profession expands in growing economies. Principles for delivering in effective in-service teacher education in other than large-scale training sessions are emerging as governments analyze how they invest in upskilling English-language education, particularly in Southeast and northern Asia. The growth in government investment through in-service upgrading of ELT has increased accountability as educational planners in Asia change English-language curriculum to meet the needs of developing transnational knowledge-based economies.

\section{Pedagogical Implications}

Any effective in-service teacher education experience is dependent on the relationship created between the facilitator of learning and the practicing teachers who will hopefully experience activities contributing to their ongoing professional development with, ideally, immediate direct relevance in their everyday practice in the classroom. A supportive training environment is clearly important if a teacher is going to accept new techniques, and while administrative support plays a role the initial drive comes from the teacher's own acceptance during the inservice course interaction. The $w h$ - questions provide a good starting point for in-service teacher training programs. First, one expects that teachers will learn what needs to be known: the content. An example of this is that NNESTs may have learnt English in formal teaching situations with more descriptive terms for language forms, such as varied tenses while some NESTs may not be able to name them and the functions without specific training. Adopting Pasternak and Bailey's (2006) quadrant model placing language proficiency and professional development on a continuum, in-service teacher training programs should aim to foster language proficiency of both NESTs and NNESTs in declarative and procedural domains. The how to of teaching is a second major area, while courses also need to anchor learning in the ways teachers learn how to teach. Similarly, both NESTs and NNESTS will need guidance in linking classroom processes to classroom management language and strategies especially if the in-service course is centered on deconstructing teacher-fronted teaching. The whys of pedagogy as experienced in the ways teachers learn how to teach or, in the case of some in-service education pedagogy, how they unlearn how to teach, has led to interest in teachers' exploration of self-knowledge and awareness of how teachers manage interaction through reflection.

Bringing the perspectives of lingua franca settings into teacher preparation programs, Snow, Kamhl-Stein, and Brinton (2006, p. 247) share the following suggestions which can be infused into in-service settings:

- Expose teachers and, ultimately, learners to varieties of English beyond the inner circle; ]

- Help to deconstruct the myth of the native speaker and offer participants opportunities to recognize and value themselves as intercultural speakers;

- Integrate methodologies that are valued in the local context and reflect students' actual needs and interests;

- Align teacher preparation with the needs of learners in schools;

- Be guided by local conceptualizations of what constitutes professionalism;

- Foster language development through increased target language exposure, consciousness-raising activities, and overt feedback;

- Provide teachers opportunities to progress along the continuum of professionalism through exposure to standards and a variety of professional development opportunities; 
- Encourage collaboration between local and outside experts; and

- Instill in participants the value of ongoing reflective practice and lifelong learning.

Teacher collaboration is also regarded as a viable route for effective in-service teacher development, making positive contributions to increased student achievement. While collaboration and collaborative practices are seen as tools that can be integrated into formal and informal in-service training structures and experiences, teacher educators should never forget that it may also be a site of tension and conflict for traditionally juxtaposed and seemingly "different" teacher populations-NESTs and NNESTs. Therefore, any sort of collaborative practice within in-service training schemes needs to explicitly define roles, expectations, and responsibilities for everyone involved; include different ways, experiences, and structures to deal with teachers' attitudes towards collaboration; and acknowledge and capitalize individuals' contextualized strengths and areas of improvement. Ultimately, these practices lead to forming stronger relationships, greater responsibility towards collaboration, increased accountability towards stakeholders involved in collaboration, and ultimately, enhanced teacher autonomy promoting internalization of professional development as a lifelong enterprise.

SEE ALSO: Collaboration and Collaborative Practices; Dichotomy or Continuum Perspectives; Divide Between NESTs and NNESTs: Teacher Education Programs in Preparing NESTs and NNESTs; Teacher Qualifications, Professionalism, Competencies, and Benchmarks

\section{References}

Bailey, K. M. (2006). Language teacher supervision. Cambridge, England: Cambridge University Press.

Borg, S. (2011). The impact of in-service education on language teachers' beliefs. System, 39, $370-80$.

Farrell, T. S. C. (2013). Reflective teaching. Alexandria, VA: TESOL Press.

Hall, S. J. (2013). Learning from teacher educators: Reflecting on the certainty of teaching "recipes." The English Teacher, XLII, 137-51.

Holliday, A. (2006). The struggle to teach English as an international language. Oxford, England: Oxford University Press.

Mann, S., \& Hau, H. T. E. (2012). The role of mentoring in supporting novice English language teachers in Hong Kong. TESOL Quarterly, 46(3), 472-95.

Pasternak, M., \& Bailey, K. M. (2004). Preparing nonnative and native English-speaking teachers: Issues of professionalism and proficiency. In L. D. Kamhi-Stein (Ed.), Learning and teaching from experience: Perspectives on nonnative English-speaking professionals (pp. 155-75). Ann Arbor: University of Michigan Press.

Snow, M., Kamhl-Stein, L. \& Brinton,P. (2006). Teacher training for English as a lingua franca. Annual Review of Applied Linguistics, 26, 261-281. 
Waters, A., \& Vilches, M. L. C. (2010). "Tanggap, tiklop, tago" (receive, fold, keep): Perceptions of best practice in ELT INSET. London, England: British Council.

\section{Suggested readings}

Dogancay-Aktuna, S., \& Hardman, J. (2008). Teaching and teacher education: Praxis and possibilities. Alexandria, VA: TESOL Press.

Trent, J., Gao, X., \& Gu, M. (2014). Language teacher education in a multilingual context. Dordrecht, Netherlands: Springer. 